\title{
ENTRE OS MODELOS HEGEMÔNICOS E OS NECESSÁRIOS ROMPIMENTOS PARA A RETOMADA DA DEMOCRACIA
}

\section{AMONG THE HEGEMONIC MODELS AND THE NECESSARY DISRUPTIONS TO THE RESUMPTION OF DEMOCRACY}

\author{
Leilane Tolentino Stauffer*
}

SANTOS, Boaventura de Souza. A difícil democracia: reinventar as esquerdas. 1. ed. São Paulo: Boitempo, 2016. 224 p.

A dificil democracia, de Boaventura de Sousa Santos, joga luz em diversas contradições, disputas, normas, direitos e caminhos a partir de experiências de países que construíram o entendimento acerca da democracia. Mais do que isso, o autor nos convida a refletir sobre as relações dúbias de poder, presentes em nossos dias, que deslegitimam a soberania popular, princípio central e regente da democracia.

A partir do próprio título da obra, o sociólogo português, cujas pesquisas e publicações dedicam-se à sociologia do direito, à teoria pós-colonial, à interculturalidade e aos direitos humanos, já nos indica pistas do percurso histórico que o livro percorrerá e do seu posicionamento diante da efervescência e dos conflitos políticos espalhados pelo mundo. A começar pela própria definição e pelos rumos da democracia.

Pelas concepções hegemônicas de democracia, o autor sugere uma caracterização a partir de alguns princípios fundadores e centrais. Entre eles está a valorização positiva da apatia política, na qual circula a defesa de que o cidadão não teria capacidade nem interesse para a política. A ele cabe somente escolher os líderes responsáveis pelas decisões políticas. Destacamos aqui, também, a oposição das noções de mobilização e institucionalização, a discussão a respeito do pluralismo, enxergado como forma de incorporação partidária e disputa entre elites.

Motivado, então, pelo questionamento para onde vai a democracia, feito justa-

\footnotetext{
* Mestranda do Programa de Pós-Graduação em Estudos de Linguagens do Centro Federal de Educação Tecnológica de Minas Gerais - CEFGET ־- (Belo Horizonte/MG/Brasil). E-mail: leilanetstauffer@gmail.com.
} 
mente por grupos sociais que compartilham os valores do Estado Democrático de Direito e que reivindicaram, entre 2011 e 2013, a "democracia real" e a "democracia já", Santos observa a presença de ações e forças antidemocráticas que esvaziaram os propósitos populares da democracia como regime de governo. Em prognóstico interessante mostrado pelo autor a partir de estudos do sociólogo estadunidense Immanuel Wallerstein, afirma que países do sul da Europa - especialmente Portugal, Grécia e Espanha - e da América Latina se encontram em uma posição semiperiférica no sistema mundial, na intermediação entre as nações centrais e as periféricas e, assim, tendem a ser caracterizados por instabilidades políticas. Como reflexo, ao longo do século XX, viveram um percurso político marcado por turbulências, “[...] oscilando entre períodos de democracia mais ou menos restritiva e períodos de ditadura civil ou militar" (p. 7).

Santos lança a reflexão de que "vivemos em sociedades politicamente democráticas e socialmente fascistas" (p. 13) e destaca as dominações do capitalismo financeiro, do colonialismo e do patriarcado presentes nas relações sociais. Dividido em quatro partes - além de contar com o epílogo, cujo título é Para ler em 2050 -, o livro fornece análise de problemas e caminhos encontrados por países em diferentes partes do globo que, de alguma forma, relacionaram-se com a democracia. 0 ponto de partida escolhido por Santos não poderia ser outro senão seu próprio país. 0 autor examina a situação histórica de Portugal, a partir de seu texto publicado em 1990. Nele, observamos os desdobramentos da Revolução dos Cravos, em 1974, e as transformações vividas pelo Estado português frente aos desenvolvimentos políticos da Europa.

No segundo capítulo, intitulado As mar- cas do tempo, podemos conferir as experiências políticas de Cuba e refletir sobre o restabelecimento do conceito de esquerda. Por esquerda o autor entende o conjunto de posições políticas que defende a noção de que todos os seres humanos têm o mesmo valor, devendo ser esse valor o mais alto. Entende, ainda, como sendo o conjunto de práticas e teorias que se opõe à expansão do capitalismo e a relações econômicas, políticas, sociais e culturais oriundas dele. Ainda no segundo capítulo, Santos disponibiliza um conjunto de textos comentando situações e movimentos em diferentes partes do mundo relacionados à democracia. Sobre o Brasil, comenta as manifestações de junho de 2013 e pontua a existência de dois Brasis. 0 primeiro Brasil, desenvolvimentista, é marcado por uma boa imagem pública internacional deixada na gestão do ex-presidente Lula com as políticas de inclusão social. 0 segundo se formava a partir de três temporalidades e narrativas. A primeira é a narrativa da exclusão social, do sistema oligárquico, da presença das elites políticas racistas, preconceituosas e restritas, “[...] uma narrativa que remonta à colônia e até hoje se tem reproduzido sobre formas sempre mutantes" (p. 96). A segunda narrativa é a da força que reivindica a favor da democracia participativa. E a terceira narrativa se situa nos dez anos de investimento nas políticas de inclusão social, redução da pobreza, criação da classe média com poder de consumo e reconhecimento das discriminações.

0 terceiro capítulo traz duas entrevistas que foram publicadas em 2010 e em 2016 na Espanha e na Itália. 0 autor defende que a democracia precisa existir expandindo sua concepção do sistema político, alcançando também o sistema econômico, as relações familiares, raciais, sexuais, re- 
gionais, religiosas, de vizinhança, comunitárias. Atrelada a essa concepção, Santos pontua que

a igualdade tem muitas dimensões e só pode ser plenamente realizada se, a par da igualdade, se lutar pelo reconhecimento das diferenças, ou seja, pela transformação das diferenças desiguais (que criam hierarquias sociais) em diferenças iguais (que celebram a diversidade social como forma de eliminar as hierarquias). (p. 80)

No quarto capítulo, intitulado Cartas às esquerdas, Santos registra treze cartas, escritas entre agosto de 2011 e junho de 2016, nas quais reflete a necessidade de reinventar as esquerdas e reforça o pensamento de que "temos o direito a ser iguais quando a diferença nos inferioriza; temos o direito a ser diferentes quando a igualdade nos descaracteriza" (p. 155).

Ao apontar as formas de dominação capitalista, colonialista e patriarcal, o autor deixa claro que essas opressões, apesar de suas peculiaridades, atuam de maneira sistêmica, conjunta, em rede. A respeito do capitalismo, podemos aproximá-lo de um dos debates sobre a democracia pós-Segunda Guerra Mundial ressaltado por Santos. Trata-se de um questionamento básico sobre as condições estruturais da democracia: haveria compatibilidade entre democracia e capitalismo? 0 autor retoma a discussão inaugurada por Barrington Moore (1996), em 1960, que indicava, por meio de uma tipologia, países com e sem propensão democrática. Santos pontua que para Moore o papel do Estado diante da modernização e a relação com as classes agrárias explicariam por que poucas nações possuíam regimes democráticos no início da segunda metade do século XX. Pela visão marxista, é in- compatível democratizar a relação entre o capital e o trabalho nas sociedades capitalistas. Foi, então, que se passou a discutir modelos de democracia alternativos ao liberal, como a democracia participativa, a democracia popular e a democracia desenvolvimentista.

Santos observa que, na história, países da América Latina com regime de democracia representativa sofreram desgastes e os fatores convergiam na transformação da democracia liberal para a democracia neoliberal. A democracia liberal reconhece a existência de dois mercados de valores, o mercado político com diversidade de ideias e valores ideológicos que não são quantificáveis e são responsáveis por conduzir os ideais democráticos, e o mercado econômico, com valores que têm preço, estabelecido pelos bens e serviços. A democracia neoliberal, por sua vez, tem como foco o mercado dos valores econômicos e, assim, os valores políticos são regidos pela lógica de um mercado de ativos econômicos. Por isso, o autor pontua que "uma sociedade é capitalista não porque todas as relações econômicas e sociais são capitalistas, mas porque elas determinam o funcionamento de todas as outras relações econômicas e sociais existentes na sociedade" (p. 81). Na sequência, o autor denuncia que as democracias neoliberais estão se transformando em formas de legitimação do neoliberalismo.

[...] os direitos sociais a saúde, educação e segurança social estão a transformar-se em escandalosos privilégios; os sistemas políticos estão a ser insidiosamente corrompidos para atender exclusivamente aos interesses das facções dominantes do capital; [...] (p. 162). 
Ao discutir o colonialismo, torna-se clara a lógica do racismo e do não-reconhecimento do outro. Podemos aproximar essa dimensão dominadora com o exemplo dado por Santos, ao contextualizar a história de ascensão de países centrais da Europa, incluindo os nórdicos. A defesa deles consistia em afirmar que a melhor forma de preservar as políticas de inclusão social defendidas pela social-democracia, como educação e saúde pública, previdência social, transportes públicos, seria proibindo e restringindo que elas fossem adotadas pelas periferias. A lógica contraditória possui, inclusive, uma duração histórica, já que "no passado (desde o fim da Segunda Guerra Mundial), a social-democracia européia como um todo só foi possível devido à exploração violenta das colônias e das ex-colônias" (p. 10).

Por patriarcado, identificamos o sistema social que, imbricado às duas outras dimensões de opressão, estabelece a dominação e a supremacia do homem patriarca, entendido como superior à mulher nas instâncias públicas e privadas. Percebemos, aqui, diversas formas de violência que repercutem em abusos e privilégios. Santos observa que as sociedades capitalistas são fortemente marcadas por sistemas de relações desiguais de poder, entre eles o sexismo, o racismo, a homofobia, a xenofobia. Cidadãos, classes e grupos são vítimas de mais de uma forma de dominação e opressão. Por conta disso, o autor entende que a luta contra as formas de dominação deve também ser promovida em rede. "Democratizar significa transformar relações desiguais de poder em relações de autoridade partilhada" (p. 80).

Apesar das conjunturas desfavoráveis apresentadas, não acreditamos que a obra de Santos se caracterize por um viés apocalíptico. Ao contrário. Pelas suas reflexões, o autor nos convida a democratizar a democracia, a radicalizá-la, e propõe que essa retomada seja feita pelo caminho da participação popular. 0 autor chama atenção para o princípio da demodiversidade, conceito do qual parte para trabalhar as concepções de democracia. 0 princípio pode ser observado na primeira década do século XXI, em que foram criadas na América Latina condições políticas para debater o pluralismo e a diversidade democrática. Tais condições foram viabilizadas pela chegada ao poder de partidos de esquerda e de centro-esquerda em países como a Venezuela, o Brasil, a Argentina, o Equador, a Bolívia e o Uruguai.

0 princípio da demodiversidade corresponde à legitimação de outras formas de deliberação democrática. Consiste em experimentar articulações entre democracia representativa, participativa e comunitária. E, mais do que isso, ampliar os campos democráticos, não se restringindo ao campo político liberal, que, como o autor situa, "transforma a democracia política numa ilha democrática em arquipélago de despotismos: a fábrica, a família, a rua, a religião, a comunidade, os mass media, os saberes, etc" (p. 145).

Ao defender a necessidade de radicalizar a democracia, o autor afirma a importância de intensificar o contraste com o capitalismo, mesmo reconhecendo que a dificuldade desse processo se concentra no campo da luta democrática, caracterizado pela heterogeneidade e cujas forças interiores fascistas e socialistas se confrontam. 0 fascismo a que o autor se refere está marcado por relações sociais de poder desiguais que, "no contexto social e político em que ocorrem, a parte (indivíduos ou grupos) mais poderosa exerce um direito de veto sobre aspectos essenciais da vida da parte menos poderosa” (p. 132). 
Para Santos, o entendimento da democracia não pode ser reduzido a procedimentalismo, igualdades formais e direitos cívicos e políticos, “[...] pois por via deles nunca foi possível estender as potencialidades distributivas, tanto simbólicas como materiais, da democracia às classes populares que mais poderiam beneficiar-se delas" ( $p$. 18). Por isso, o autor assegura a necessidade de entender a democracia como "uma nova gramática social que rompa com o autoritarismo, o patrimonialismo, o monolitismo cultural, o não reconhecimento da diferença; tal gramática social implica um enorme investimento nos direitos econômicos, sociais e culturais” (p. 18). São enfatizados seis subcampos de relações sociais nos quais a democratização exerce papel importante: o espaço-tempo doméstico, o espaço-tempo da produção, o espaço-tempo da comunidade, o espaço-tempo do mercado, o espaço-tempo da cidadania e o espaço-tempo mundial das relações entre Estados.

Santos sugere pensar com audácia caminhos para responder o capitalismo e as crises oriundas dele. Além de democratizar, o autor indica o caminho por meio de outras duas palavras-chave: desmercantilizar e descolonizar. A desmercantilização está ligada à prática de desnaturalizar o pensamento capitalista que valoriza o capital em diversas instâncias, como na economia social, comunitária e popular, nas cooperativas e no controle público dos recursos e serviços que impactam o bem-estar dos cidadãos. 0 foco, de acordo com o autor, concentra-se em "impedir que a economia de mercado alargue seu âmbito até transformar a sociedade numa sociedade de mercado (na qual tudo se compra e tudo se vende, incluindo valores éticos e opções políticas)" (p. 145).

A respeito da descolonização, o autor pontua a necessidade de desnaturalizar o racismo e denunciar o grande conjunto de técnicas, práticas e instituições que o reproduzem. Santos chama atenção para muitas formas de racismo presentes na sociedade: na imprensa, na moda, nos aparelhos formadores - como a escola, a família, a polícia e a religião -, nos estereótipos e no medo, no sexo, nas músicas, metáforas e piadas, na concepção do belo, do apropriado, do inteligente, no recrutamento de empregados, entre inúmeras outras situações de convívio social.

Desmercantilizar, democratizar e descolonizar significam refundar os conceitos de justiça social, incluindo na igualdade e na liberdade o reconhecimento da diferença (para além do relativismo e do universalismo), a justiça cognitiva (a ecologia dos saberes) e a justiça histórica (a luta contra o colonialismo estrangeiro e o colonialismo interno) (p. 145).

Ao ampliar o conceito de justiça, a tendência é que seja promovida a tensão entre o que Santos chama de guerra da história e da memória, isto é, o embate entre forças que estabelecem o silenciamento e forças que enfatizam o que não pode ser esquecido, o que deve ser evidenciado.

\section{Referências}

MOORE, B. Social Origins of Dictatorship and Democracy: Lord and Peasant in the Making of the Modern World. Boston: Beacon, 1996.

Recebido em: 25.04.18

Aprovado em: 24.08.18 